\title{
Competition Between and Within Universities: Theoretical and Experimental Investigation of Group Identity and the Desire to Win
}

\author{
Zhuoqiong (Charlie) Chen ${ }^{\text {a }}$ \\ David Ong b,* \\ Roman Sheremeta ${ }^{c, d}$ \\ ${ }^{\text {a }}$ London School of Economics, Houghton Street, London, WC2A, 2AE, UK \\ ${ }^{\mathrm{b}}$ Peking University, University Town, Shenzhen, 518055, P.R.C \\ ${ }^{\mathrm{c}}$ Case Western Reserve University, 11119 Bellflower Road, Cleveland, OH 44106, USA \\ ${ }^{\mathrm{d}}$ Economic Science Institute, Chapman University
}

October 21, 2015

\begin{abstract}
We study how salient group identity, created through competition between students from different universities, as well as differences in the value of winning impact competitive behavior. Our experiment employs a simple all-pay auction within and between two university subject pools. We find that when competing against their peers, students within the lower tier university bid more aggressively than students within the top-tier university. Also, students from the lower tier university, in particular women, bid more aggressively when competing against students from the top-tier university. These findings, interpreted through a theoretical model incorporating both group identity and differential value of winning, suggest that students at the lower tier university have a stronger group identity as well as higher desire to win.
\end{abstract}

Keywords: experiments, all-pay auction, competitiveness, group identity JEL Classifications: C91, D03, J7, Z13

* Correspondence to: dvdong@ gmail.com, Tel: +86-755-2603-2655, Fax: +86-755-2603-5344

We thank Kai Konrad for his generous support of David Ong's visit to the Max Plank Institute of Tax Law and Public Finance, where the initial idea for this study was developed. We also thank Bram Cadsby, Christopher Cotton, Daniel Houser, Kai Konrad, Dylan Minor, Amnon Rapoport, Marie-Claire Villeval, Aner Sela, Nathaniel Wilcox, Charles Zheng, and Zhong (Zachary) Zemin for their helpful comments, and Hong (Hannah) Lin who assisted in conducting the experiment. 


\section{Introduction}

The higher education system is composed of many highly diverse universities of various sizes and quality which are in constant competition between each other (Clotfelter, 1999; De Fraja and Iossa, 2002). These universities pay substantial amounts of money to attract faculty who would enhance the university's prestige (Melguizo and Strober, 2007) and head coaches who would make more successful sports franchises (Kahn, 2007). As a result of these efforts to vertically differentiate, there is more competition among students to enter more prestigious universities (Epple et al., 2006). This entry of competitive students in turn increases the competition between students within universities (Barsky, 2002).

The purpose of this study is to examine theoretically and empirically how group identity and the desire to win influence student competition between and within universities. Our data come from an experiment conducted at two different universities located in the same city. Shenzhen University is ranked roughly among the top 100 universities and University Town is ranked among the top 10 universities in China. ${ }^{1}$ Students at both universities participated in a two-player all-pay auction. Before choosing their bids, students learned the school identity of their opponent, which was either the same or different than their own school. Our theory allows us to separate the effect of group identity on competition between universities and the effect of the value of winning on competition within universities.

We hypothesized that competition between universities, regardless of differences in rank, would be enhanced by group identity. ${ }^{2}$ According to social identity theory (Tajfel and Turner,

\footnotetext{
${ }^{1}$ University Town is the graduate campus of Peking, Tsinghua and HIT Universities. Our subjects are from the Peking and Tsinghua universities, which are generally recognized as the top-two universities in China. Though HIT is of lower rank in its undergraduate student population, the graduate school at University Town is of similar prestige. For simplicity, we will refer to the University Town campus as a university.

${ }^{2}$ We restrict our attention to school identity which is the most salient group identity in our setting.
} 
1979), a salient group identity may cause individuals to put themselves and others into different categories based on perceived similarities and differences, leading to discrimination between ingroup and out-group members. The degree of discrimination depends on the saliency of group identity. ${ }^{3}$ Both theoretical (Akerlof and Kranton, 2000, 2005) and experimental studies (Chen and $\mathrm{Li}, 2009)$ have supported the predictions of the social identity theory. For example, experimental studies show that enhanced group identity increases kindness and pro-social behavior towards in-group members, while inducing more hostile behavior towards out-group individuals (Abbink et al., 2012; Cason et al., 2012; Halevy et al., 2012). ${ }^{4}$ The implication of the latter is that salient group identity may stiffen the competition between different social groups, such as universities.

Group identity, however, cannot explain variations in the level of competition between students within the same university. Enhanced group identity should increase pro-social behavior towards in-group members, thus reducing (not increasing) competitiveness of students. Variations in the level of competition within different universities could be driven by many factors, both monetary and non-monetary, related to ability or related to temperament. There is significant interest in the non-ability/temperamental characteristics, e.g., level of ambition, by which schools select students and how these characteristics may complement or substitute for ability; see the literature spawned by Dale and Krueger (2002). There is evidence that nonmonetary rewards are important for students (Biggs, 1982). Indeed, recent theoretical (Dubey and Geanakoplos, 2010) and field work (Jalava et al., 2015) shows that students are driven by

\footnotetext{
${ }^{3}$ Various methods have been used to induce saliency of group identity in economics experiments. Chen and $\mathrm{Li}$ (2009) provide an excellent literature review on group identity.

${ }^{4}$ The effect of salient group identity on individual behavior has been examined in nonstrategic tasks (Chen and Li, 2009), as well as strategic tasks such as public goods games (Eckel and Grossman, 2005), bargaining games (McLeish and Oxoby, 2011), prisoner's dilemma games (Charness et al., 2007), and group conflicts (Cason et al., 2012).
} 
non-monetary prizes in form of a rank-based test scores. Moreover, there is substantial experimental literature documenting that non-pecuniary incentives in the form of status (Charness et al., 2013; Clingingsmith and Sheremeta, 2015), recognition (Andreoni and Petrie, 2004; Samek and Sheremeta, 2014) and non-monetary rewards (Sheremeta, 2010; Price and Sheremeta, 2011, 2015; Brookins and Ryvkin, 2014) are effective at inducing more competitive behavior. Therefore, we hypothesized that competition between students within the same university is motivated by the "desire to win" measured by the value of winning.

In within-school bidding, we find that when competing against their peers, students within Shenzhen University bid more aggressively than students within University Town. In between schools bidding, students from Shenzhen University (a lower tier university) bid more aggressively when competing against students from University Town (a higher tier university). Interpreted through a theoretical model which incorporates both group identity and differential value of winning, our data indicate that students at both schools reveal a higher desire to win when facing students from the other school, suggesting that group identity impacts competitive behavior of students. Further analysis indicates that this result is primarily driven by female students at the lower tier university.

Previous studies have suggested that students are driven by the potential individual returns to education (Psacharopoulos, 1981; Heckman et al., 2006; Cunha and Heckman, 2007) and social returns (Moretti, 2004). We find that students are also driven by group identity and the desire to win. These two factors alone can explain not only the level of competition between universities, but also the variation in the level of competition between students within the same university. 
We present the theoretical model and derive the predictions in Section 2. Section 3 describes the experimental design and procedures, while Section 4 presents the results. Finally, we discuss implications of our results in Section 5.

\section{Theoretical Predictions}

All-pay auctions are often used to model real life contests when the costs of competing are unrecoverable (Hillman and Riley, 1989; Ellingsen, 1991; Baye et al., 1996). In a standard two player all-pay auction with complete information, player 1 with higher value of winning $V_{1}$ submits bid $b_{1}$ and player 2 with lower value $V_{2}$ submits bid $b_{2}$. The player who submits the highest bid wins the auction and receives the corresponding prize. However, both players have to pay their bids irrespectively of who wins the auction (hence the term "all-pay auction"). Therefore, player 1's (similarly player 2's) payoff function is given by:

$$
\pi_{1}\left(b_{1}, b_{2}\right)= \begin{cases}V_{1}-b_{1} & \text { if } b_{1}>b_{2} \\ 0-b_{1} & \text { if } b_{1} \leq b_{2}\end{cases}
$$

Hillman and Riley (1989) showed that the mixed strategy equilibrium for the asymmetric all-pay auction with complete information and two risk neutral players is characterized by the following two equations:

$$
\left\{\begin{array}{l}
\left(V_{2}-b\right) G_{1}(b)+(-b)\left(1-G_{1}(b)\right)=0 \\
\left(V_{1}-b\right) G_{2}(b)+(-b)\left(1-G_{2}(b)\right)=V_{1}-V_{2}
\end{array} .\right.
$$

Here, $G_{1}(b)$ is the probability that player 1 bids lower than $b$ and $G_{2}(b)$ the probability that player 2 bids lower than $b$.

An intuitive derivation follows. In any equilibrium, the higher value player 1 can always bid the lower value $V_{2}$ and win, getting $V_{1}-V_{2}$ with certainty. The lower value player 2 can always bid zero and get at least zero. Neither can get more than what they can guarantee because 
of competition. Equations described by (2) show that in a mixed strategy Nash equilibrium, players must make each other indifferent between what they can get for sure (the right hand side of the equation) and what they can get by any bid (the left hand side). From (2), we can solve for the equilibrium cumulative distribution functions or the "bidding functions":

$$
\left\{\begin{array}{ll}
G_{1}(b)=\frac{b}{V_{2}} & \text { for } b \in\left[0, V_{2}\right] \\
G_{2}(b)=\frac{V_{1}-V_{2}+b}{V_{1}} & \text { for } b \in\left[0, V_{2}\right]
\end{array} .\right.
$$

Using the equilibrium bidding functions (3), we can calculate the average expected bid by player 1 and player 2:

$$
\left\{\begin{array}{l}
E\left(b_{1}\right)=\frac{V_{2}}{2} \\
E\left(b_{2}\right)=\frac{V_{2}}{2} \frac{V_{2}}{V_{1}} .
\end{array}\right.
$$

Note that if players have the same value of winning, i.e., $V_{1}=V_{2}=V$, then in equilibrium both players should randomly choose their bids between 0 and $V$, and the average bid should be $V / 2$, resulting in full dissipation of the prize and zero expected payoffs for both players.

Obviously, the actual value of winning may not necessarily be reflected by the pure monetary value of the prize (Chen et al., 2015). Instead, it most likely incorporates different nonmonetary considerations, such as the non-monetary utility of winning (Sheremeta, 2010, 2013, 2015), status (Charness et al., 2013; Clingingsmith and Sheremeta, 2015), and recognition (Andreoni and Petrie, 2004; Samek and Sheremeta, 2014). Moreover, since our experiment is conducted at two different universities (Shenzhen University and University Town), group identity may also impact individual behavior in the all-pay auction (Chen and Li, 2009; Abbink et al., 2012; Cason et al., 2012; Halevy et al., 2012), especially when students from one 
university compete against students from another university. Our theoretical model considers both types of factors simultaneously.

We begin by noting that students from different universities may have different value of winning, $V_{S}$ for students at Shenzhen University and $V_{U}$ for students at University Town. Also, when competing against each other, different universities may have different group identity, $I_{S}$ for students at Shenzhen University and $I_{U}$ for students at University Town. We assume that both the value of winning and group identity linearly impact individual utility.

When students from one university compete with students from the same university, we should not expect any impact of group identity $\left(I_{S}=I_{U}=0\right)$ on individual behavior. However, students at different universities may value winning differently $\left(V_{S} \neq V_{U}\right)$. In such a case, at Shenzhen University we have an all-pay auction between two symmetric players $S$ and $S^{\prime}$. Therefore, the payoff function of player $S$ (similarly player $S^{\prime}$ ) is given by:

$$
\pi_{S S}\left(b_{S}, b_{S^{\prime}}\right)= \begin{cases}V_{S}-b_{S} & \text { if } b_{S}>b_{S \prime} \\ 0-b_{S} & \text { if } b_{S} \leq b_{S^{\prime}}\end{cases}
$$

Similarly, at University Town we have an all-pay auction between two symmetric players $U$ and $U^{\prime}$. Therefore, the payoff function of player $U$ (similarly player $U^{\prime}$ ) is given by:

$$
\pi_{U U}\left(b_{U}, b_{U \prime}\right)= \begin{cases}V_{U}-b_{U} & \text { if } b_{U}>b_{U \prime} \\ 0-b_{U} & \text { if } b_{U} \leq b_{U}\end{cases}
$$

When students from one university compete against students from another university, in addition to different values of winning $\left(V_{S} \neq V_{U}\right)$, we should expect more competitive behavior against students from another university $\left(I_{S}>0\right.$ and $\left.I_{U}>0\right)$ due to identity enhanced hostile behavior towards out-group members (Abbink et al., 2012; Cason et al., 2012; Halevy et al., 2012). In such a case, we have an all-pay auction between two asymmetric players $S$ (a student 
from Shenzhen University) and $U$ (a student from University Town). Player $S$ 's payoff function is given by:

$$
\pi_{S U}\left(b_{S}, b_{U}\right)=\left\{\begin{array}{ll}
V_{S}+I_{S}-b_{S} & \text { if } b_{S}>b_{U} \\
0-b_{S} & \text { if } b_{S} \leq b_{U}
\end{array} .\right.
$$

Similarly, player $U$ 's payoff function is given by:

$$
\pi_{U S}\left(b_{S}, b_{U}\right)=\left\{\begin{array}{ll}
V_{U}+I_{U}-b_{U} & \text { if } b_{U} \geq b_{S} \\
0-b_{U} & \text { if } b_{U}<b_{S}
\end{array} .\right.
$$

Using the payoff functions (5) through (8) and the equilibrium analysis described in (1) through (4) we can derive theoretical predictions for our experiment. Obviously, such predictions depend on the assumptions about the value of winning $\left(V_{S}\right.$ and $\left.V_{U}\right)$ and group identity $\left(I_{S}\right.$ and $\left.I_{U}\right)$. For convenience, we use "bid" to refer to the "average bid" (since the equilibrium bid is defined by a mixed strategy). Also, for convenience, $b_{S S}, b_{S U}, b_{U S}$, and $b_{U U}$ refer to the average bids by Shenzhen University students against Shenzhen University students, Shenzhen University students against University Town students, University Town students against Shenzhen University students and University Town students against University Town students. Table 1 provides theoretical predictions based on the assumption that Shenzhen University students and University Town students differ in their value of winning the auction $\left(V_{S}\right.$ vs. $\left.V_{U}\right)$ and group identity $\left(I_{S}\right.$ vs. $\left.I_{U}\right)$.

For within-school treatments SS and UU, the average bids depend on the relative magnitude of values $V_{S}$ and $V_{U}$. For example, if $V_{S}>V_{U}$ then it has to be the case that $b_{S S}>b_{U U}$, since $b_{S S}=\frac{V_{S}}{2}$ and $b_{U U}=\frac{V_{U}}{2}$. Similarly, if $V_{S}<V_{U}$ then it has to be the case that $b_{S S}<b_{U U}$. These predictions are shown in the first row of Table 1. The average bids from between schools treatments SU and US, however, depend on the joint effect of valuation and identity, $V_{S}+I_{S}$ and $V_{U}+I_{U}$. We explain the predictions in Table 1 by providing one example based on the two 
following assumptions: $V_{S}>V_{U}$ and $V_{S}+I_{S}>V_{U}+I_{U}$ (i.e., the second column of Table 1). Since $V_{S}>V_{U}$, equation (4) predicts $b_{S S}=\frac{V_{S}}{2}$ and $b_{U U}=\frac{V_{U}}{2}$, implying $b_{S S}>b_{U U}$. Also, since $V_{S}+I_{S}>V_{U}+I_{U}$, equation (4) predicts $b_{S U}=\frac{V_{U}+I_{U}}{2}$ and $b_{U S}=\frac{V_{U}+I_{U}}{2} \frac{V_{U}+I_{U}}{V_{S}+I_{S}}$, implying $b_{S U}>$ $b_{U S}$ and $b_{S U}>b_{U U}$. Finally, depending on the exact values of parameters, $b_{U S}$ could be $>,<$ or $=$ $b_{S S}$ and $b_{U U}$, hence we have $<=>$ in $b_{S S}$ vs. $b_{U S}$ and $b_{U S}$ vs. $b_{U U}$.

Table 1: Theoretical Bids by Pairs.

\begin{tabular}{ccccc}
\hline \multicolumn{5}{c}{ Value $V$, Identity $I$} \\
\hline School Pairs & $V_{S}+I_{S}<V_{U}$ & $V_{S}>V_{U}$ & $V_{S}<V_{U}$ & $V_{S}<V_{U}$ \\
\hline$b_{S S}$ vs. $b_{U U}$ & $>$ & $V_{S}+I_{S}>V_{U}+I_{U}$ & $V_{S}+I_{S}<V_{U}+I_{U}$ & $V_{S}+I_{S}>V_{U}+I_{U}$ \\
$b_{S S}$ vs. $b_{U S}$ & $<$ & $>$ & $<$ & $<$ \\
$b_{S S}$ vs. $b_{S U}$ & $<=>$ & $<=>$ & $<$ & $<=>$ \\
$b_{S U}$ vs. $b_{U U}$ & $<=>$ & $<=>$ & $<=>$ & $<$ \\
$b_{S U}$ vs. $b_{U S}$ & $<$ & $>$ & $<=>$ & $>$ \\
$b_{U S}$ vs. $b_{U U}$ & $>$ & $>$ & $<$ & $<=>$ \\
\hline
\end{tabular}

The entire set of predictions is shown in Table 1. Note that there are two comparisons necessary to distinguish one set of assumptions from the rest: $b_{S S}$ vs. $b_{U U}$ and $b_{S U}$ vs. $b_{U S}$. For example, to distinguish $V_{S}>V_{U}$ and $V_{S}+I_{S}>V_{U}+I_{U}$ from the rest, we need $b_{S S}>b_{U U}$ and $b_{S U}>b_{U S}$. We make use of this fact when we analyze data from our experiment.

\section{Experimental Design and Procedures}

We recruited a total of 329 subjects, 167 subjects (97 males, 70 females) from Shenzhen University and 162 subjects (62 males, 100 females) from University Town. Subjects were paired randomly and anonymously into four pairings: SS (98 subjects), SU (69 subjects), US (68 subjects), and UU (94 subjects). 
The experiment was conducted in the standard lecture hall. We gave monitors envelopes according to rough estimates of the number of people in each lecture hall. Each envelope contained a bidding sheet with instructions (available in Appendix) in which subjects were informed that they had $10 \mathrm{CNY}$ and could bid for additional $10 \mathrm{CNY}$ in an all-pay auction. For a comparison, a student assistant makes 10-15 CNY per hour.

On the bidding sheet, subjects could mark a bid ranging from 0 to $10 \mathrm{CNY}$ in $0.5 \mathrm{CNY}$ increments. The winner got the prize of $10 \mathrm{CNY}$. Bids of zero always gave subjects the endowment of $10 \mathrm{CNY}$. We gave subjects 10 examples of bids and corresponding payoffs, allowing 2 minutes for questions and answers. There was a place on the bidding sheet for students to write down their name and account information. The instructions told the students to put the bidding sheet back into the envelope. We transferred payments to their accounts after we finished all sessions of the experiment.

\section{Results}

\subsection{Group Identity and the Value of Winning}

Figure 1 shows the average bid in the all-pay auction experiment by school pair. If we were to assume that there are no differences in the value of winning between schools $\left(V_{S}=V_{U}\right)$ and group identity $\left(I_{S}=I_{U}\right)$, then there should be no differences in behavior across four pairs. However, this is not what we observe.

Not only at the aggregate level, but also at the individual level we see the differences in behavior of different pairs. Figure 2 shows the distribution of bids by school pair. The standard theoretical prediction (Hillman and Riley, 1989; Baye et al., 1996) is that risk neutral players competing for the prize value of 10 should choose their bids randomly from 0 and 10 . However, 
as it can be seen from Figure 2, in all four pairs the distribution of bids is not uniform. The Kolmogorov-Smirnov test against the theoretical uniform distribution generates p-values less than 0.01 for all four pairs. This finding is consistent with the vast experimental literature on allpay auctions (Dechenaux et al., 2015).

\section{Figure 1: Average Bid by School Pair.}

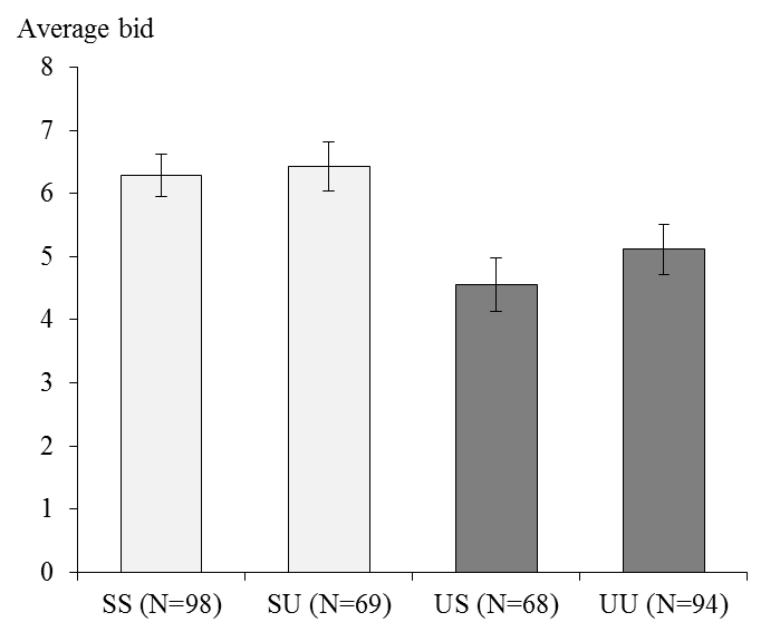

Figure 2: Distribution of Bids by School Pair.
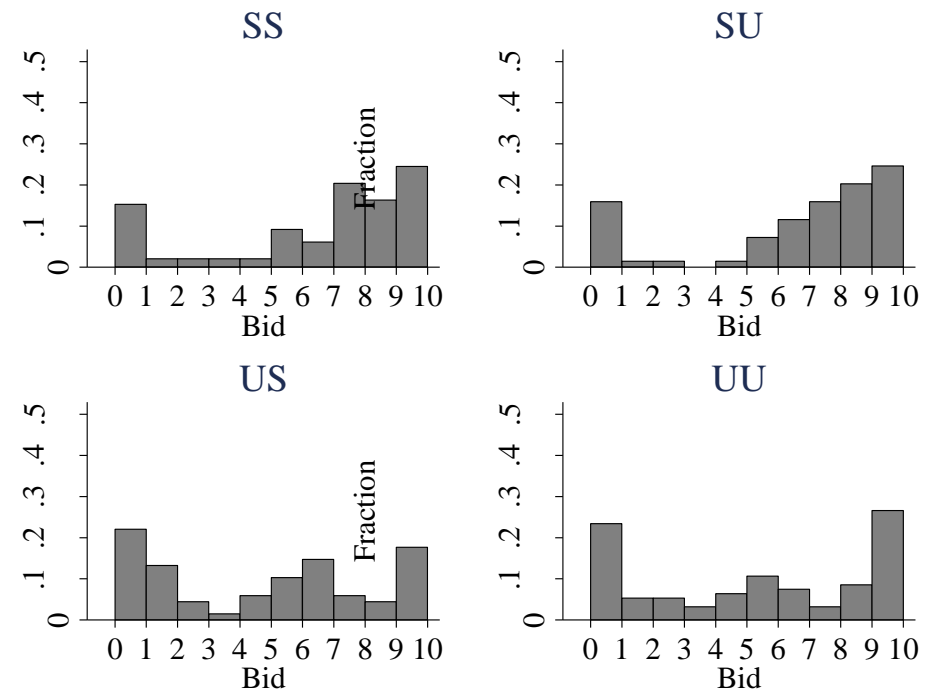

Table 2 provides comparison of average bids between different school pairs. We find different average bids depending on the pair. Based on the Wilcoxon rank-sum test, S students 
against S students (SS) bid significantly more than U students against U students (UU) and significantly more than $\mathrm{U}$ students against $\mathrm{S}$ students (US). Also, we find that $\mathrm{S}$ students against U students (SU) bid significantly more than U students against U students (UU) and significantly more than $\mathrm{U}$ students against $\mathrm{S}$ students (US). However, we do not find any significant differences when comparing SS with SU, or when comparing US with UU.

Table 2: Comparison of Average Bids between School Pairs.

\begin{tabular}{ccc}
\hline Average Bid & $p$-value & Sign \\
\hline SS vs. UU & 0.06 & $>$ \\
SS vs. US & 0.00 & $>$ \\
SS vs. SU & 0.79 & $=$ \\
SU vs. UU & 0.05 & $>$ \\
SU vs. US & 0.00 & $>$ \\
US vs. UU & 0.46 & $=$ \\
\hline
\end{tabular}

We can identify the relative magnitude of the effect from group identity as well as the value of winning by fitting the data to the theoretical predictions in Section 2. Note that the results in Table 2, i.e., the comparison of average bids by school pairs, are only consistent with column two in Table 1, i.e., the theoretical predictions under the assumptions that $\mathrm{S}$ has higher value of winning, $V_{S}>V_{U}$, and the joint effect of the value of winning and group identity is also higher for $\mathrm{S}$, that is $V_{S}+I_{S}>V_{U}+I_{U}$. Based on such identifications, it is now possible to separate the effect of group identity from the value of winning. Recall that group identity only affects average bids in across school bidding. Given that $b_{S S}=\frac{V_{S}}{2}=6.29$ and $b_{U U}=\frac{V_{U}}{2}=5.11$, we can infer that $V_{S}=12.58$ and $V_{U}=10.22$. Given that $V_{S}+I_{S}>V_{U}+I_{U}$ and $b_{S U}=\frac{V_{U}+I_{U}}{2}=$ 6.43, we can infer that $V_{U}+I_{U}=12.86$, which further implies $I_{U}=12.86-V_{U}=2.64$. Similarly, given that $b_{U S}=\frac{V_{U}+I_{U}}{2} \frac{V_{U}+I_{U}}{V_{S}+I_{S}}=4.56$, we can infer that $V_{S}+I_{S}=18.13$, which further 
implies $I_{S}=18.13-V_{S}=5.55$. Thus, we conclude that $V_{S}>V_{U}$ and $I_{S}>I_{U}$, implying higher value of winning as well as higher group identity for students at Shenzhen University.

\subsection{Gender Differences}

In our experiment, we also recorded the gender of all participants. It has been well documented that gender plays an important role in competitive environments. For example, when choosing to be rewarded by a tournament payment scheme or a piece-rate, women tend to choose the piece-rate over the tournament (Niederle and Vesterlund, 2007; Cason et al., 2010; Balafoutas and Sutter, 2012; Sutter and Glätzle-Rützler, 2015). However, in auctions and contests, women actually bid more than men (Ham and Kagel, 2006; Casari et al., 2007; Chen et al., 2013; Mago et al., 2013; Chen et al., 2015; Price and Sheremeta, 2015). Therefore, Figure 3 splits the average bid in the all-pay auction by school pair and gender.

Figure 3: Average Bid by School Pair and Gender.
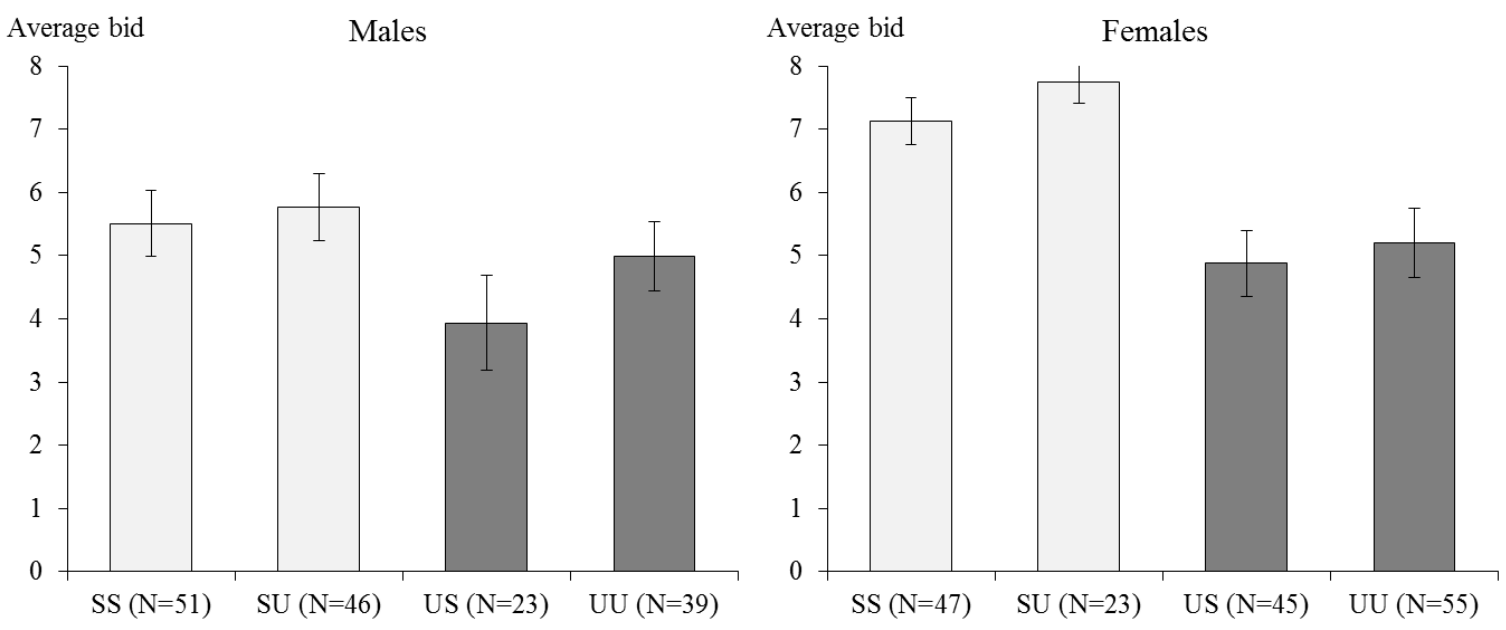

We find significant differences between males and females in Shenzhen University, with women bidding significantly more than men (Wilcoxon rank-sum test, $\mathrm{p}$-value $=0.07$ for SS pairs and p-value=0.06 for SU pairs). This is consistent with the previous findings in the auction and 
contest literature. The behavior of men and women is more similar in University Town (Wilcoxon rank-sum test, $\mathrm{p}$-value $=0.29$ for US pairs and $\mathrm{p}$-value $=0.68$ for UU pairs).

Table 3: Comparison of Average Bids between School Pairs of Females.

\begin{tabular}{ccc}
\hline Average Bid & $p$-value & Sign \\
\hline SS vs. UU & 0.07 & $>$ \\
SS vs. US & 0.00 & $>$ \\
SS vs. SU & 0.53 & $=$ \\
SU vs. UU & 0.03 & $>$ \\
SU vs. US & 0.00 & $>$ \\
US vs. UU & 0.80 & $=$ \\
\hline
\end{tabular}

Table 4: Comparison of Average Bids between School Pairs of Males.

\begin{tabular}{ccc}
\hline Average Bid & $p$-value & Sign \\
\hline SS vs. UU & 0.44 & $=$ \\
SS vs. US & 0.12 & $=$ \\
SS vs. SU & 0.79 & $=$ \\
SU vs. UU & 0.30 & $=$ \\
SU vs. US & 0.08 & $>$ \\
US vs. UU & 0.29 & $=$ \\
\hline
\end{tabular}

Following the same estimation procedure done in Table 2, we provide comparison of average bids between different school pairs of females in Table 3 and of males in Table 4 . We find exactly the same treatment effects for females (compare signs in Table 2 and Table 3) but not for males (compare signs in Table 2 and Table 4). This suggests that our main treatment effects may be moderated by gender. Therefore, we conduct a regression analysis.

\subsection{Regression Analysis}

To check the robustness of our findings, we provide an additional regression analysis. Table 5 reports OLS regressions with robust standard errors, where the dependent variable is bid, 
and the independent variables are pairing dummies SS, SU and US. The omitted pairing dummy is UU, which serves as a reference point. Regression (1) confirms our earlier finding that Shenzhen University students bid more than University Town students independent of the identity of the opponent (see the significant coefficients on SS and SU). However, when we include the interactions of pairs with female dummy in regression (2), the significance disappears. Now, only the interactions $\mathrm{SS} \times \mathrm{F}$ and $\mathrm{SU} \times \mathrm{F}$ are significant, suggesting that our main treatment effects come from female students.

Table 3: OLS Regressions.

\begin{tabular}{ccc}
\hline Bid & $(1)$ & $(2)$ \\
\hline $\mathrm{SS}$ & $1.17 * *$ & 0.52 \\
& $(0.51)$ & $(0.76)$ \\
$\mathrm{SU}$ & $1.32 * *$ & 0.78 \\
& $(0.55)$ & $(0.77)$ \\
$\mathrm{US}$ & -0.55 & -1.05 \\
& $(0.58)$ & $(0.93)$ \\
$\mathrm{UU} \times \mathrm{F}$ & & 0.21 \\
& & $(0.77)$ \\
$\mathrm{SS} \times \mathrm{F}$ & & $1.62 * *$ \\
& & $(0.64)$ \\
$\mathrm{SU} \times \mathrm{F}$ & & $1.97 * * *$ \\
& & $(0.63)$ \\
$\mathrm{US} \times \mathrm{F}$ & & 0.94 \\
& & $(0.91)$ \\
Constant & $5.11 * * *$ & $4.99 * * *$ \\
& $(0.39)$ & $(0.55)$ \\
\hline $\mathrm{N}$ & 329 & 329 \\
\hline Note: $*$ indicates statistical significance at the \\
$10 \%$ level, ** significant at 5\%, and $* * *$ at $1 \%$. \\
Robust standard errors are in parentheses.
\end{tabular}

\section{Discussion and Conclusions}

We examine how salient group identity, created through competition between students from different universities, as well as differences in the value of winning impact students' 
competitive behavior. First, we find that when competing against their peers, students within the lower tier university bid more aggressively than students within the top-tier university. Second, we find that when competing against students from the other university, students from the lower tier university bid more aggressively than students from the top-tier university. Our data, interpreted through a theoretical model, indicate that students at the lower tier university have stronger group identity as well as higher desire to win.

Our results show that salient group identity, created through competition between students from different universities, impacts students' competitive behavior. One implication of this result is that, depending on the objective, the university may want to enhance their school identity by comparing their outcomes with other universities. This can be done, for example, if the objective is to improve the performance of a sports team or to increase the volume of blood donation on campus.

Perhaps a more surprising finding of our study is that students at the lower tier university, especially women, have a higher desire to win than students at the top-tier university. One way of interpreting our findings is that lower status individuals (lower school tier students or women in China) derive particular satisfaction from winning against higher status individuals (higher school tier students or men). It is also possible that women, especially in China, where families traditionally prefer boys (Attané, 2009), may suffer from low academic status and thus may be more willing to pay to win because they have a higher demand for status (Charles et al., 2009). Finally, it is possible that students at the lower tier university may have different social preferences which could impact their competitive behavior against others (Mago et al., 2015). Irrespective of the exact interpretation, our findings suggest that winning can be considered as a substitute for status or competitive social preferences. 


\section{References}

Abbink, K., Brandts, J., Herrmann, B., \& Orzen, H. (2012). Parochial altruism in inter-group conflicts. Economics Letters, 117, 45-48.

Akerlof, G.A., \& Kranton, R.E. (2000). Economics and identity. Quarterly Journal of Economics, 115, 715-753.

Akerlof, G.A., \& Kranton, R.E. (2005). Identity and the economics of organizations. Journal of Economic Perspectives, 19, 9-32.

Andreoni, J., \& Petrie, R. (2004). Public goods experiments without confidentiality: A glimpse into fund-raising. Journal of Public Economics, 88, 1605-1623.

Attané, I. (2009). The determinants of discrimination against daughters in China: Evidence from a provincial-level analysis. Population Studies, 63, 87-102.

Balafoutas, L., \& Sutter, M. (2012.) Affirmative action policies promote women and do not harm efficiency in the laboratory. Science, 335, 579-582.

Barsky, A.E. (2002). Structural sources of conflict in a university context. Conflict Resolution Quarterly, 20, 161-176.

Baye, M.R., Kovenock, D., \& De Vries, C.G. (1996). The all-pay auction with complete information. Economic Theory, 8, 291-305.

Biggs, J. (1982). Student motivation and study strategies in university and college of advanced education populations. Higher Education Research and Development, 1, 33-55.

Brookins, P., \& Ryvkin, D. (2014). An experimental study of bidding in contests of incomplete information. Experimental Economics, 17, 245-261.

Casari, M., Ham, J.C., \& Kagel, J.H. (2007). Selection bias, demographic effects, and ability effects in common value auction experiments. American Economic Review, 97, 1278-1304.

Cason, T.N., Masters, W.A., \& Sheremeta, R.M. (2010). Entry into winner-take-all and proportional-prize contests: An experimental study. Journal of Public Economics, 94, 604611.

Cason, T.N., Sheremeta, R.M., \& Zhang, J. (2012). Communication and efficiency in competitive coordination games. Games and Economic Behavior, 76, 26-43.

Charles, K.K., Hurst, E., \& Roussanov, N. (2009). Conspicuous consumption and race. Quarterly Journal of Economics, 124, 425-467.

Charness, G., Masclet, D., \& Villeval, M.C. (2013). The dark side of competition for status. Management Science, 60, 38-55.

Charness, G., Rigotti, L., \& Rustichini, A. (2007). Individual behavior and group membership. American Economic Review, 97, 1340-1352.

Chen, Y., Katuščák, P., \& Ozdenoren, E. (2013). Why can't a woman bid more like a man? Games and Economic Behavior, 77, 181-213.

Chen, Y., \& Li, S.X. (2009). Group identity and social preferences. American Economic Review, 99, 431-457.

Chen, Z., Ong, D., \& Sheremeta, R.M. (2015). The gender difference in the value of winning. Working Paper.

Clingingsmith, D., \& Sheremeta, R.M. (2015). Status and the demand for visible goods: Experimental evidence on conspicuous consumption. Working Paper.

Clotfelter, C.T. (1999). The familiar but curious economics of higher education: Introduction to a symposium. Journal of Economic Perspectives, 13, 3-12. 
Cunha, F., \& Heckman, J. (2007). The technology of skill formation. American Economic Review, 97, 31-47.

Dale, S.B., \& Krueger, A.B. (2002). Estimating the payoff to attending a more selective college: An application of selection on observables and unobservables. Quarterly Journal of Economics, 117, 1491-1527.

De Fraja, G., \& Iossa, E. (2002). Competition among universities and the emergence of the elite institution. Bulletin of Economic Research, 54, 275-293.

Dechenaux, E., Kovenock, D., \& Sheremeta, R. (2015). A survey of experimental research on contests, all-pay auctions and tournaments. Experimental Economics, forthcoming.

Dubey, P., \& Geanakoplos, J. (2010). Grading exams: 100, 99, 98,... or A, B, C? Games and Economic Behavior, 69, 72-94.

Eckel, C.C., \& Grossman, P.J. (2005). Managing diversity by creating team identity. Journal of Economic Behavior \& Organization, 58, 371-392.

Ellingsen, T. (1991). Strategic buyers and the social cost of monopoly. American Economic Review, 81, 648-657.

Epple, D., Romano, R., \& Sieg, H. (2006). Admission, tuition, and financial aid policies in the market for higher education. Econometrica, 74, 885-928.

Halevy, N., Weisel, O., \& Bornstein, G. (2012). "In-group love" and "out-group hate" in repeated interaction between groups. Journal of Behavioral Decision Making, 25, 188-195.

Ham, J.C., \& Kagel, J.H. (2006). Gender effects in private value auctions. Economics Letters, 92, 375-382.

Heckman, J.J., Lochner, L.J., \& Todd, P.E. (2006). Earnings functions, rates of return and treatment effects: The Mincer equation and beyond. Handbook of the Economics of Education, 1, 307-458.

Hillman, A.L., \& Riley, J.G. (1989). Politically contestable rents and transfers. Economics \& Politics, 1, 17-39.

Jalava, N., Joensen, J.S., \& Pellas, E. (2015). Grades and rank: Impacts of non-financial incentives on test performance. Journal of Economic Behavior \& Organization, 115, 161196.

Kahn, L.M. (2007). Markets: Cartel behavior and amateurism in college sports. Journal of Economic Perspectives, 21, 209-226.

Mago, S.D., Samak, A.C., \& Sheremeta, R.M. (2014). Facing your opponents social identification and information feedback in contests. Journal of Conflict Resolution, forthcoming.

Mago, S.D., Sheremeta, R.M., \& Yates, A. (2013). Best-of-three contest experiments: Strategic versus psychological momentum. International Journal of Industrial Organization, 31, 287296.

McLeish, K.N., \& Oxoby, R.J. (2011). Social interactions and the salience of social identity. Journal of Economic Psychology, 32, 172-178.

Melguizo, T., \& Strober, M.H. (2007). Faculty salaries and the maximization of prestige. Research in Higher Education, 48, 633-668.

Moretti, E. (2004). Estimating the social return to higher education: evidence from longitudinal and repeated cross-sectional data. Journal of Econometrics, 121, 175-212.

Niederle, M., \& Vesterlund, L. (2007). Do women shy away from competition? Do men compete too much? Quarterly Journal of Economics, 122, 1067-1101. 
Price, C.R., \& Sheremeta, R.M. (2011). Endowment effects in contests. Economics Letters, 111, 217-219.

Price, C.R., \& Sheremeta, R.M. (2015). Endowment origin, demographic effects and individual preferences in contests. Journal of Economics and Management Strategy, 24, 597-619.

Psacharopoulos, G. (1981). Returns to education: an updated international comparison. Comparative Education, 17, 321-341.

Samek, A.S., \& Sheremeta, R.M. (2014). Recognizing contributors: an experiment on public goods. Experimental Economics, 17, 673-690.

Sheremeta, R.M. (2010). Experimental comparison of multi-stage and one-stage contests. Games and Economic Behavior, 68, 731-747.

Sheremeta, R.M. (2013). Overbidding and heterogeneous behavior in contest experiments. Journal of Economic Surveys, 27, 491-514.

Sheremeta, R.M. (2015). Behavioral dimensions of contests. In Companion to Political Economy of Rent Seeking, Congleton, R.D., Hillman, A.L., Eds., London: Edward Elgar.

Sheremeta, R.M. (2015). Impulsive behavior in competition: Testing theories of overbidding in rent-seeking contests. Working Paper.

Sutter, M., \& Glätzle-Rützler, D. (2015). Gender differences in the willingness to compete emerge early in life and persist. Management Science, forthcoming.

Tajfel, H., \& Turner, J.C. (1979). An integrative theory of intergroup conflict. In The Social Psychology of Intergroup Relations, William G. Austin and Stephen Worchel, Eds., Monterey, CA: Wadsworth. 


\section{Appendix - Experimental Instructions}

\section{You are...}

Name:

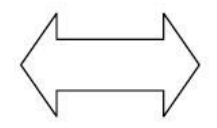

- Please write down your name in the left block

- Your opponent is also a subject in this experiment. You can find the school or school and gender of your opponent in the right block.

- We paired you and your opponent randomly before today.

- There will be an auction between the two of you.

- From now on, each of you is endowed with $10 \mathrm{CNY}$.

- When the auction begins, you will use the $10 \mathrm{CNY}$ we gave you to bid in the auction.

- The prize of this auction is $10 \mathrm{CNY}$ as well.

- Both you and your opponent can only bid once in the auction. When you decide your bid, please mark the corresponding circle on the right graph. Please mark only one circle. Marking more than one will be treated as mistake. If you do not mark any circle in the graph, you are bidding zero.

$\diamond$ Please note that if your opponent chooses a lower bid than you do, you are the winner in the auction and earn the extra $10 \mathrm{CNY}$ which is the prize of the auction. Your opponent earns no extra money since he/she loses, but he/she still has to pay his bid.

$\diamond$ In the same reasoning, if your opponent chooses a higher bid than you do, he/she will be the winner and earns the extra $10 \mathrm{CNY}$. But both of you have to pay your own bid.

$\diamond$ If the two of you choose the same bid, you will split the $10 \mathrm{CNY}$ prize and pay your own bid.

$\diamond$ If both of you bid zero, that is, both of you do not mark any circle, then none of you earns any additional payment.

- Please note that your final payment in this experiment is exactly equal to the payment after you bid using the 10 $\mathrm{CNY}$ we give you in this auction. We do not provide any other payment.

- Please now decide your bid.

- After you finish marking your bid, please write down your name and bank account in the box, and then put this paper back to the envelop.

\section{Your opponent is...}

\section{A Female student in UT}

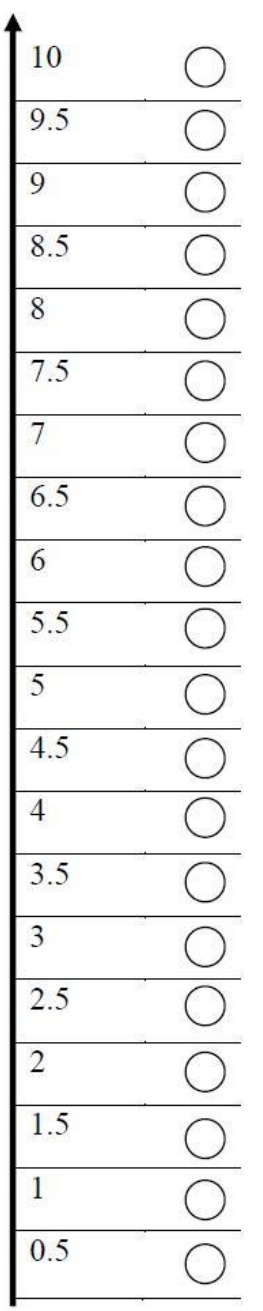

Name

Bank account No. 